\title{
Cloning and Nucleotide Sequence of the KHR Killer Gene of Saccharomyces cerevisiae
}

\author{
Kuniyasu Goto, Yasuhiro Iwatuki, Kazuyosi KiTano, \\ Takaji OBATA and Shodo Hara
}

National Research Institute of Brewing, 2-6-30 Takinogawa,

Kita-ku, Tokyo 114, Japan

Received October 2, 1989

\begin{abstract}
The $K H R$ gene cloned from a genomic library was on $4.7-\mathrm{kbp}$ DNA fragment and was inserted into YCpG11 vector (KHR-YCp) and YEp vector (KHP-YEp). Transformants with KHR-YEp could secrete 3-4 times as much killer toxin into the media as the donor strain. The complete nucleotide sequence of the $K H R$ gene was analyzed. It was found that the $K H R$ gene consisted of $888 \mathrm{bp}$. It was suggested that this protein was processed before being secreted into the media, because its molecular mass presumed from the nucleotide sequence was larger than that of the mature killer toxin.
\end{abstract}

Some yeast strains secrete into the culture media factors, called killer toxin, which kill sensitive strains of yeast. Previous reports suggested that the use of $\mathrm{K} 1$ type killer yeasts in sake making ${ }^{1)}$ and $\mathrm{K} 2$ type killer yeasts in wine making ${ }^{2)}$ would improve thier qualities.

Recently, Kitano et al. ${ }^{3)}$ described new two killer types encoded on the chromosomal DNA of $S$. cerevisiae. One of them was $K H S$ (Killer of $\underline{H}$ eat Sensitive) mapped on the right arm of chromosome $\mathrm{V}$ and the other $K H R$ (K iller of $\underline{H}$ eat $\underline{\mathrm{R}}$ esistant) on the left arm of chromosome IX. These killer activities were weaker than those of known killer strains. The isolation and characterization of $K H R$ killer toxin was described in our previous paper. ${ }^{4)}$ The mature killer toxin was a single protein having a molecular mass of about $20 \mathrm{kDa}$.

To study the function and the secretion system of $K H R$ killer toxin in comparison with other killer toxin, the elucidation of its primary structure is necessary. We report here the molecular cloning and the nucleotide sequence of the $K H R$ gene.

\section{Materials and Methods}

Strains, plasmids, and media. S. cerevisiae No. $18 \rho^{-}(a$
$K H R K H S$ ) was used as the DNA donor to construct a gene library, $S$. cerevisiae No. $111(\alpha K H R k h s)$ as the standard KHR strain, S. cerevisiae DBY746 ( $\alpha$ leu2-3 leu2-112 trp1 ura3 his $3 \mathrm{khr} k \mathrm{ks}$ ) as a recipient strain for transformation. E. coli JA221, and MV1184 were used as hosts, plasmid YCpG11, 5. as a vector for the construction of a gene library, and YEp24, ${ }^{6)}$ pUC118, pUC119, and $\mathrm{M} 13-\mathrm{KO}^{7)}$ as vectors for DNA sequencing and DNA manipulation.

LB supplemented with $100 \mu \mathrm{g} / \mathrm{ml}$ ampicillin and $40 \mu \mathrm{g} / \mathrm{ml}$ 5-bromo-4-chloro-3-indolyl- $\beta$-D-galactopyranoside (X-gal) was used for selection of $E$. coli transformants.

YNBD medium consisted of $2 \%$ dextrose, $0.67 \%$ yeast nitrogen base without amino acids, $0.04 \%$ each of Lmethionine and L-leucine, and $0.008 \% \mathrm{~L}$-histidine. YNBD media supplemented with $0.008 \% \mathrm{~L}$-tryptophan and uracil (YNBD +) were used for selection of yeast transformants with YEp24 and YCpG11 derivative vectors respectively. The medium consisting of YNBD+ in $50 \mathrm{~mm}$ citratephosphate buffer $(\mathrm{pH} 6.0)$ and $0.003 \%$ methylene blue were used for the killer assay. For agar plates, $2 \%$ agarose was added to each medium.

\section{Construction of a YCPGII library}

Genomic DNA of $S$. cerevisiae No. $18 \rho^{-}$was prepared by the method of Cryer et $a l^{8)}$ partially digested with $\operatorname{Sau} 3 A$, and separated by agarose-gel electrophoresis. Four to ten kbp DNA fragments were collected and directly inserted into YCpG11 BamHI site.

PFGE and Southern hybridization. Electrophoresis was done at $12^{\circ} \mathrm{C}$ on a LKB 2015 Pulsaphor hexagonal system with $0.5 \times$ TBE buffer ( $45 \mathrm{~mm}$ Tris base, $45 \mathrm{~mm}$ boric acid, $1 \mathrm{~mm}$ EDTA) containing $1.5 \%$ agarose at $300 \mathrm{~V}$, for $40 \mathrm{hr}$ 
with a switching interval of $100 \mathrm{sec}$. Gels were stained with ethidium bromide for $10 \mathrm{~min}$ at a concentration of $0.5 \mu \mathrm{g} /$ $\mathrm{ml}$ in $0.5 \times \mathrm{TBE}$, and destained overnight in $0.5 \times \mathrm{TBE}$.

Southern transfer and hybridization were done by the method of Maniatis et al. ${ }^{97}$ A 1.9-kbp BamHI-Pst I fragment prepared from $\mathrm{KHR}-\mathrm{YCp}$ was used as the $K H R$ probe. The probe was labeled with $\left[\alpha-{ }^{32} \mathrm{P}\right] \mathrm{dCTP}$ by nicktranslation.

Yeast transformation. Transformation was done by the method of Ito et al. ${ }^{10}$

Assay for killer activity. The cells for the assay were grown on killer assay plates for 2 days at $25^{\circ} \mathrm{C}$, and then C. glabrata IFO0622 was sprayed over the plates. After incubation at $20^{\circ} \mathrm{C}$ for 2 days, the fungicidal zone around each colony was observed. Killer activity was measured as described before. ${ }^{4)}$

Nucleotide sequencing analysis. Genomic DNA was subcloned using plasmids pUC118, pUC119, and E. coli MV1184. The nucleotide sequence was analyzed by the dideoxy method of Messing ${ }^{11}$ and by the fluorescentlabeled DNA sequence method ${ }^{12)}$ using an automated DNA sequencing system (Applied Biosystems Model $370 \mathrm{~A})$. The nucleotide sequence and amino acid sequence were analyzed with the GENETYX Program (SDC Co., Ltd., Japan).

\section{Results}

\section{Cloning of the KHR gene}

Abut 5,000 clones (Amp ${ }^{\mathrm{r}}$ and $\mathrm{Tet}^{\mathrm{s}}$ ) were selected from $E$. coli transformants with the YCpG11 vector containing $S$. cerevisiae No. $18 \rho^{-}$yeast DNA fragments partially digested with $\operatorname{Sau} 3 A$. These recombinant plasmids were amplified in $E$. coli JA221, purified, and stored as the gene banks. From about 9,000 nontryptophan-requiring yeast clones, one clone was selected by killer activity at $\mathrm{pH}$ 6.0. This clone had also the same characteristics as the $K H R$ killer toxin, for example, the optimum $\mathrm{pH}$, temperature stability, and antimicrobial spectrum $^{4)}$ like those produced by $S$. cerevisiae No. 111.

The plasmid was prepared from this killer yeast clone and was designated KHR-YCp. The inserted DNA fragment was about 4.7 $\mathrm{kbp}$.

The KHR-YCp DNA was digested with several restriction enzymes to make a restric-

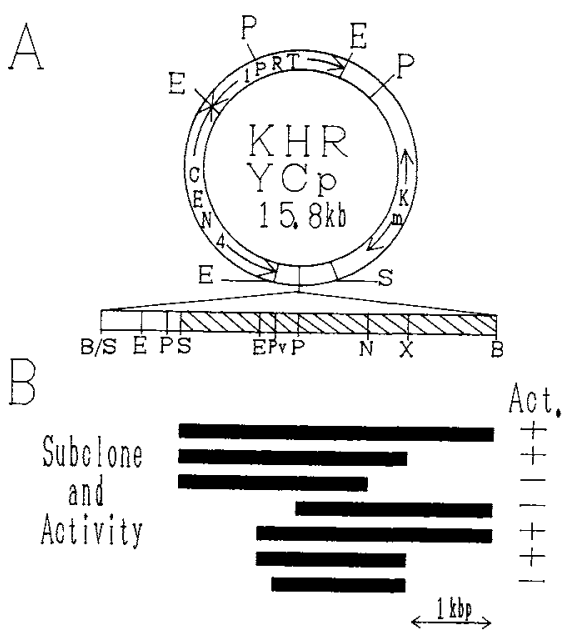

Fig. 1. The Structure of Plasmid KHR-YCp and Subcloning Fragments.

A: The 4.7-kb $\operatorname{Sau} 3 A$ fragment containing the entire $K H R$ gene was inserted into YCpG11 (11.1 kbp).

$\mathrm{B}$ : Subcloning fragments were as indicated by solid lines.

These fragments were inserted into YEp24 vector and examined their killer activities. Their $K H R$ killer activities are positive $(+)$ or negative $(-)$.

Abbreviations: B, Bam HI; E, EcoRI; N, NcoI; P, PstI; Pv, $P v u \mathrm{II}$ S, SalI; B/Sau, the ligation site of BamHI and Sau3 A; X, XhoI.

tion map (Fig. 1). By the physical mapping (Fig. 2), this fragment was located on chromosome IX, which was the same as the genetic mapping. ${ }^{3)}$

Construction of a plasmid carrying an internal region of $K H R$

In the preliminary experiments, the biologically functional $K H R$ gene was found on a part of the BamHI-SalI fragment (about $3.7 \mathrm{kbp}$ ) in $\mathrm{KHR}-\mathrm{YCp}$.

The DNA was recovered from $B a m \mathrm{HI}-S a l I$ digestion of KHR-YCp and then inserted into plasmid vectors pUC118 and 119 and YEp24 (Fig. 3). The resultant pUC (KHR-pUC) and YEp (KHR-YEp) were used for sequencing, subcloning, and testing of the killer activity respectively.

The $E$. coli transformants with KHR-pUC and KHR-YEp did not express the killer activity.

The growth of the yeast transformant with KHR-YEp was inhibited at the optimum con- 


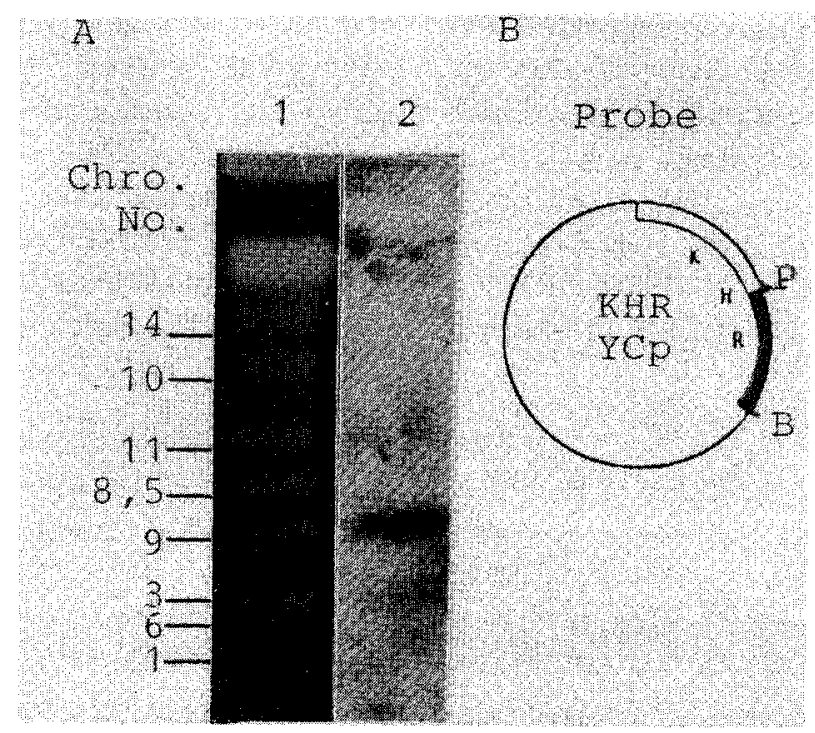

Fig. 2. Physical Mapping of KHR Gene in S. cerevisiae No. $18 \rho^{-}$.

A: lane 1, the gel was stained with ethidium bromide; lane 2 , the $1.9 \mathrm{kbp}$ fragment containing the $K H R$ gene was used as the probe.

B: The open and solid boxes indicated the insert DNA. The $1.9 \mathrm{kbp}$ fragment treated by $P s t \mathrm{I}$ and Bam HI (the solid box) was used as the probe.

Abbreviations: P, Pst I; B, Bam HI

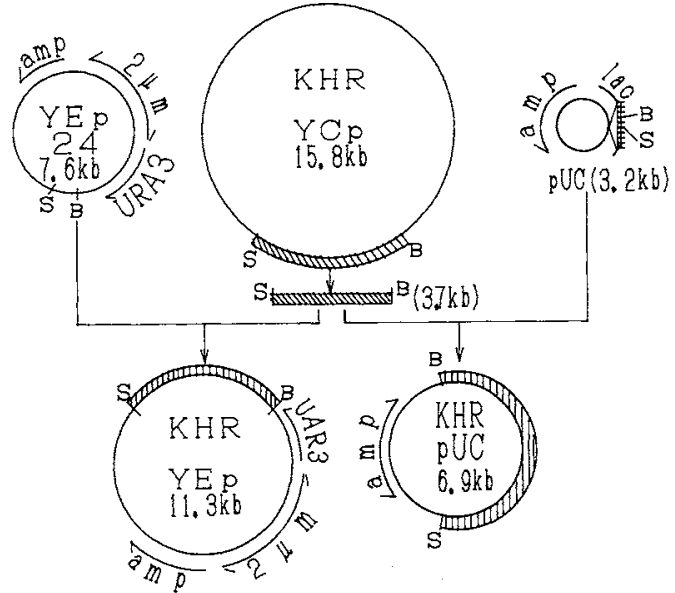

Fig. 3. The Strategies for Constructions of KHR(BS)pUC119 and KHR-YEp.

ditions for producing $K H R$ toxin, but the cell growth was not inhibited below $\mathrm{pH} 5.0$ or by shaking culture, under those conditions the $K H R$ toxin was inactivated. Those phenomena were the same as observed in the KHR multiploid strains. ${ }^{4)}$

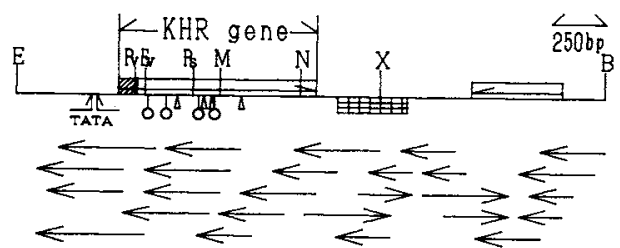

Fig. 4. The Structure of the $S$. cerevisiae Genome Surrounding $K H R$ Gene and the Strategy for Its DNA Sequencing.

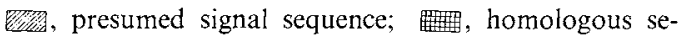
quence to $\delta$-sequence; $\delta$, Asn-X-Thr/Ser presumed glycosylation site; $\triangle$, presumed recognizing site with $K E X 2$ proteinase; $\rightleftarrows$, length and direction in sequencing; $\square$, $5^{\prime} \rightarrow 3^{\prime}$ direction of the ORFs'.

Abbreviations: E, EcoRI; Pv, PvuII; Ev, EcoRV; Ps, Pst I; M, MluI; N, NcoI; X, XhoI; B, BamHI; S, SalI.

Subcloning of the KHR gene and their expression

In subcloning, we selected yeast transformants with KHR-YEp derivatives by the complementation of $u$ ra 3 on the $\mathrm{pH} 4.5$ agar plate and the extent of the fungicidal zone formed on the killer assay plate.

Figure 1 shows the relationship between 
transformants with YEp carrying $K H R$ gene fragments and their killer activities. The functional KHR gene was found on the EcoRIXhoI fragment (about $1.7 \mathrm{kbp}$ ).

The nucleotide sequence around the KHR gene

The inserted DNA of BamHI-EcoRI fragment was sequenced as described in Materials and Methods. Figure 4 shows the sequencing strategy and summarizes the open reading frame and other information on BamHIEcoRI fragment DNA.

In this fragment, two open reading frames existed. The sequence around the XhoI site (about 350 nucleotides) had more than $85 \%$ homology to the $\delta$ sequence that was a part of *

aat.cca.att.act.aac.att.cgc.aac.aca.ttc.atc.aat.gtt.taa.tat.tta.aac.ggc. $\overline{t a t} \cdot \mathbf{a t a}$ *6 1

ttt.cgc.ggt.agg.aca. atg. tac. taa.aac. atg. aaa.ggc.cac.gga. aaa. aaa. aat.cga.tac.aaa $* 121$

taa. gca.cac. atc, ata, gtc. ATG. GGC. CAC. TTA. GCG. ATC. CTT. TTC. AGT. ATT. ATC. GCT. GTA. TTG Met-G|y-His-Leu-A!a-I!e-Leu-Phe-Ser-||e-||e-A|a-Val-Leu

* 181

AAT. ATA. GCT \ACA. GCT $\downarrow G T T$, GCA $\downarrow T C G . A G C$. GAC. AGC. ATT. TAC, CTT, AAG, GGA. CAC. AGA. GTA. GGA Asn-I|e-A|a-Thr-A|a-Va|-A|a-Ser-Ser-Asp-Ser-||e-Tyr-Leu-Lys-G|y-His-Arg-Va|-G|y *241

CAG. GAT. ATC. GAC. AGT. CTA. TAC. AGA. GTG. TAC. GAT. AAT. GGT. ACT. ATG. TAC. CCT. GTC. ACT. TTC Gin-Asp-lle-Asp-Ser-Leu-Tyr-Arg-Val-Tyr-Asp-Asn*Gly-Thr-Met-Tyr-Pro-Val-Thr-Phe *301

AAT. GAG. TGG. TTA. AAT. GAT. CTA. ACT. GGG. ATG. AAT, GAC, TTG. GCA. ACA. AAT. AAC. GCG. ACA. ATA Asn-Glu-Trp-Leu-Asn-Asp-Leu-Thr-Gly-Met-Asn-Asp-Leu-Ala-Thr-Asn-Asn*Ala-Thr-l|e $* 361$

TTA. AAA. CGT. GAC. AGT. AGC. GAT. GTT. TCT. TGC. GTT. ACT. GAA. ACA. TGC. CAA. TAC. GTG. GAT. TAC Leu-Lys+Arg-Asp-Ser-Ser-Asp-Val-Ser-Cys-Val-Thr-Glu-Thr-Cys-Gin-Tyr-Val-Asp-Tyr *421

CAC. GTG. GAT. GAC. GAA. GGA. GTT. ATA. ACT. ATA. GAC. ATA. TCT. ACG. TAT. CGT. ATC. CCT. GTC. GAA

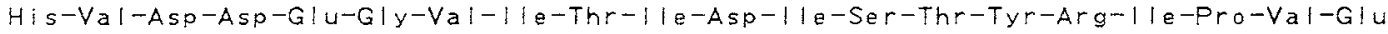
*481

TGG. GAT. AGT. GGT. TCT, GCA. GGC. AAC. GCA. TCA. TAT. GGA. GTC. TCA. AAG. CGT, GAT. ACA. AAA. TAT Trp-Asp-Ser-Gly-Ser-Ala-G|y-Asn*Ala-Ser-Tyr-Gly-Val-Ser-Lys+Arg-Asp-Thr-Lys-Tyr *541

GAG. ACA. TTC, TGT. AAG. AAG. AAA. ATA, TGC, GGT, ATA, AAC, GTT, TCC, GGT. TTC, TGT, AAC, GCG. TAT Glu-Thr-Phe-Cys-Lys+Lys+Lys-|le-Cys-G|y-||e-Asn*Val-Ser-G|y-Phe-Cys-Asn-A|a-Tyr $* 601$

GAC. TTC. GCC. GTT. CAT. GCT. TTC. GAC. TTC. GGT. GGG. AGT. GTC. TAC. AAC. CCT. GTT. AGT. GGT. ATC Asp-Phe-Ala-Val-His-Ala-Phe-Asp-Phe-G|y-G|y-Ser-Val-Tyr-Asn-Pro-Val-Ser-G|y-|le *661

ACT, GAT. AGG. ATT. AAA, GAA. GCT. ACG. AAG. AGG. GAT. AAG, ACT, GAA, TGT, CTA. GGT, TAC. GAA, CTA Thr-Asp-Arg-| le-Lys-G|u-Ala-Thr-Lys+Arg-Asp-Lys-Thr-G|u-Cys-Leu-G|y-Tyr-G|u-Leu * 721

GAT. CAT. GTG. AGA. ATA. GAT. CCT. GCT. GTT. GAT. TGG. TCC. ATA. TCT. ATT. TCT. ACT. TGG. AAA. CAA Asp-His-Val-Arg-1 le-Asp-Pro-Ala-Val-Asp-Trp-Ser-11e-Ser-11e-Ser-Thr-Trp-Lys-Gin *781

GGG. TCG. GCC, AAT. TGT. GAC. ACA. CAG. GCA. TCT. GCT, GAC. AGC. TTG. AAA. TGT. GCT. GCC, CAA. AAA G $|y-S e r-A| a-A s n-C y s-A s p-T h r-G|n-A| a-S e r-A|a-A s p-S e r-L e u-L y s-C y s-A| a-A|a-G| n-L y s$ *841

GCA. CTT. GAA, AGT, GAA. CAC. AAT. CAC. CAA, AAA. ACA. GCT, TTC. TGT. ATT. CAC. CTA. GAT. AAT, GGT Ala-Leu-Giu-Ser-G|u-His-Asn-His-Gin-Lys-Thr-Ala-Phe-Cys-1le-His-Leu-Asp-Asn-G|y *901

GGA. TCA. TTT. AAC. TTA. GAC. ATT. AGG. CTA. ATA. TCT. GAG. CTT. TCA. TTT. TCG. AAA. TAT. AAC. CCA Gly-Ser-Phe-Asn-Leu-Asp-I|e-Arg-Leu-l|e-Ser-Glu-Leu-Ser-Phe-Ser-Lys-Tyr-Asn-Pro *961

TGG. GCT. CTT. CCA. TGT. CCG. AAG. TAC, AAA. GGC. TCC. AAT. TCT, TGG. CAA, GTT. GTG. AGC, GAC. TGT Trp-Ala-Leu-Pro-Cys-Pro-Lys-Tyr-Lys-G|y-Ser-Asn-Ser-Trp-G|n-Val-Val-Ser-Asp-Cys *1021

TTT. CAA. TAA. att.aaa.caa. at t. caa.gct.cta. tta.cat. tat.caa. tct.gtt.gga, ata. aaa. t $a$ Phe $-G \mid n-S$ top

Fig. 5. Nucleotide Sequence and Deduced Amino Acid Sequence of the KHR Gene of S. cerevisiae.

Protein-coding sequence are given in uppercase letters. The TATA box is overlined; the presumed signal peptide is underlined (presumed cleavage site is indicated by an arrow); * indicates Asn-X-Thr/Ser site; + indicates presumed cleavage recognizing site with $K E X 2$ proteinase. 
transposon yeast $(T y l)$.

The nucleotide and amino acid sequence of the KHR gene

In the EcoEI-XhoI fragment, a sole ORF existed.

Figure 5 shows the nucleotide sequence and the predicted amino acid sequence of the $K H R$ gene. This ORF consisted of $888 \mathrm{bp}$, with no intron. A typical eucaryotic promoter region was found in the $K H R$ gene. A TATATA sequence, which seems to function as a TATA box, was found about $80 \mathrm{bp}$ upstream of this ORF.

The total amino acid sequence of $K H R$ deduced from its nucleotide sequence $K H R$ protein was supposed to consist of 296 amino acids. As shown in Fig. 5, a presumed signal peptide consisting of $17-21$ amino acids was found at the N-terminal side, and a 4 glycosylated amino acid sequence, Asn-X-Thr/Ser, was found at the $\mathrm{N}$-terminal side. The calculated molecular mass of this coding protein was $32,781 \mathrm{Da}$.

\section{Discussion}

Here we reported the molecular cloning and the nucleotide sequence of the genomic $K H R$ gene of $S$. cerevisiae. The $K H R$ gene is contained within the $1.7-\mathrm{kbp} E c o$ RI-XhoI fragment (Figs. 1 and 4). By the physical mapping of $K H R$ gene, it was found to be located on chromosome IX as was already reported by the genomic mapping.

The nucleotide sequence of the genomic $K H R$ gene was analyzed and it was found that the $K H R$ gene consisted of 888 bp (a molecular mass of about $33 \mathrm{kDa}$ ). This gene and presumed amino acid sequence had no homology to previously reported yeast killer genes or killer toxins, and this gene was unique as far as we searched in the EMBL and NBRF-PDB data bases.

The molecular mass of mature killer toxin was about $20 \mathrm{kDa}^{4}{ }^{4}$ The gap between these molecular masses indicated that the processing step existed during maturation of killer toxin. Remarkable findings were that the 21 very hydrophobic amino acids that were supposed to make a signal sequence existed in the $\mathrm{N}$ terminal site region, and 4 competent sites for glycosylation were located at the $\mathrm{N}$-terminal side, and 5 cleavage sites that might be cut by $K E X 2$ proteinase existed in the KHR gene.

The AT-rich region, which seems to function as a TATA box, was found upstream of the $K H R$ gene. Downstream from this gene, a

Table I. Comparision of Codon Usage Between KHR Toxin and K 1 Killer Toxin

\begin{tabular}{|c|c|c|c|c|c|c|c|c|c|c|c|c|c|c|c|}
\hline$K H R$ & $\mathrm{~K} 1$ & & & $K H R$ & $\mathrm{~K} l$ & & & $K H R$ & $\mathrm{~K} 1$ & & & $K H R$ & $\mathrm{Kl}$ & & \\
\hline \multirow[t]{2}{*}{ Phe } & UUU & 3 & 9 & Ser & UCU & 8 & 2 & Tyr & UAU & 5 & 8 & Cys & UGU & 8 & 3 \\
\hline & UUC & 8 & 2 & & $\mathrm{UCC}$ & 3 & 2 & & $\mathrm{UAC}$ & 9 & 3 & & UGC & 3 & 3 \\
\hline \multirow[t]{6}{*}{ Leu } & UUA & 4 & 7 & & UCA & 4 & 6 & non & UAA & 1 & 0 & non & UGA & 0 & 0 \\
\hline & UUG & 3 & 3 & & $\mathrm{UCG}$ & 3 & 4 & & $\mathrm{UAG}$ & 0 & 1 & Trp & UGG & 6 & 9 \\
\hline & CUU & 5 & 3 & Pro & $\mathrm{CCU}$ & 4 & 5 & $\mathrm{His}$ & $\mathrm{CAU}$ & 2 & 7 & Arg & $\mathrm{CGU}$ & 3 & 6 \\
\hline & CUC & 0 & 2 & & $\mathrm{CCC}$ & 0 & 0 & & $\mathrm{CAC}$ & 6 & 4 & & $\mathrm{CGC}$ & 0 & 0 \\
\hline & CUA & 6 & 6 & & $\mathrm{CCA}$ & 2 & 5 & Gin & $\mathrm{CAA}$ & 6 & 4 & & $\mathrm{CGA}$ & 0 & 0 \\
\hline & CUG & 0 & 4 & & $\mathrm{CCG}$ & 1 & 2 & & $\mathrm{CAG}$ & 2 & 3 & & $\mathrm{CGG}$ & 0 & 0 \\
\hline \multirow[t]{3}{*}{ Ile } & AUU & 6 & 8 & Thr & $\mathrm{ACU}$ & 8 & 3 & Asn & $\mathrm{AAU}$ & 10 & 11 & Ser & $\mathrm{AGU}$ & 7 & 8 \\
\hline & AUC & 5 & 7 & & $\mathrm{ACC}$ & 0 & 7 & & $\mathrm{AAC}$ & 7 & 8 & & $\mathrm{AGC}$ & 5 & 2 \\
\hline & AUA & 10 & 5 & & $\mathrm{ACA}$ & 8 & 10 & Lys & AAA & 10 & 3 & Arg & $\mathrm{AGA}$ & 3 & 2 \\
\hline Met & AUG & 3 & 6 & & $\mathrm{ACG}$ & 2 & 5 & & $\mathrm{AAG}$ & 7 & 10 & & $\mathrm{AGG}$ & 3 & 1 \\
\hline \multirow[t]{4}{*}{ Val } & GUU & 9 & 4 & $\mathrm{Ala}$ & GCU & 10 & 5 & Asp & GAU & 14 & 11 & Gly & GGU & 8 & 11 \\
\hline & GUC & 4 & 5 & & $\mathrm{GCC}$ & 3 & 8 & & $\mathrm{GAC}$ & 12 & 10 & & GGC & 3 & 8 \\
\hline & GUA & 2 & 8 & & GCA & 6 & 8 & Glu & GAA & 8 & 8 & & GGA & 5 & 3 \\
\hline & GUG & 5 & 8 & & GCG & 3 & 4 & & $\mathrm{GAG}$ & 3 & 6 & & $\mathrm{GGG}$ & 3 & 1 \\
\hline
\end{tabular}


sequence homologous to the $\delta$ sequence was found, but no sequence homologous to the $T y$ gene containing $\delta$ was found.

The homologies of nuclestide and amino acid sequences between the KHR and $\mathrm{Kl}$ type ${ }^{14)}$ killer toxin were not found. Table I shows the comparison of their codon usage and amino acid composition. In the $\mathrm{K} 1$ type killer preprotoxin gene, for example, such rare codons as CUC and CUG for Leucine ${ }^{14)}$ were used, but these codons were not used in the $K H R$ gene, and more common codons were used in it.

Of the $K H R$ killer toxin, the hydrophobic amino acid residues were a little fewer than those of $\mathrm{K} 1$ killer toxin. The $\mathrm{K} 1$ killer subunit which is the domain of killer activity has two hydrophobic regions and their function is an ionophore, but the $K H R$ toxin did not have a clear hydrophobic region. These data suggest that the mechanism of the $K H R$ toxin killing sensitive strains was different from that of $\mathrm{Kl}$ type killer. We are studying this killer's physiological function now.

The KHR-YEp plasmid had some useful characteristics. For example, the killer activity serves as a positive marker for $S$. cerevisiae. It has the two PvuII sites, one of which is near the end of the signal peptide and the other is within the plasmid YEp24. By digestion with $P v u$ II, the domain of KHR killer activity was cut out, and the $K H R$ promoter and its almost entire signal sequence remained intact on the YEp vector. The resultant linear DNA can be used as a secretion vector. The KHR-YEp vector had a sole $M l u I$ site in the domain of $K H R$ toxin activity. By insertion of other DNA fragment into this site, the killer activity was lost, and transformants with this vector can be selected from those with KHR-YEp by growth under the optimum $K H R$ toxin producing condition.

Acknowledgment. We thank Dr. Kojima for his kind supply of the plasmid YCpGI1.

\section{References}

1) K. Ouchi, T. Nisiya and H. Akiyama, J. Ferment. Technol., 61, 631 (1983).

2) S. Hara, Y. Iimura and K. Otsuka, Am. J. Enol. Vitic., 31, 28 (1980).

3) K. Kitano, in "The Biotechnology of Yeast," Gakkai Syuppan Center, Tokyo, 1988, pp. 1-8.

4) K. Goto, T. Iwase, K. Kichise, K. Kitano, A. Totuka, T. Obata and S. Hara, Agric. Biol. Chem., 54, 505 (1990).

5) K. Sakai and M. Yamamoto, Agric. Biol. Chem., 50, 1177 (1986).

6) D. Botstein and R. W. Davis, in "The Molecular Biology of the Yeast Saccharomyces," Cold Spring Harbor Lab., New York, 1982, pp. 607-636.

7) J. Viera and J. Messing, in "Methods in Enzymology," Vol. 153, ed. by R. Wu and L. Grossman, Academic Press, New York, 1987, pp. 3-11.

8) D. F. Cryer, R. Eccleshall and J. Marmur, in "Methods in Cell Biology," Vol. 12, ed. by D. M. Prescott, Academic Press, New York, 1973, pp. 39-44.

9) T. Maniatis, E. F. Fritsch and J. Sambrook, in "Molecular Cloning-A Laboratory Manual," Cold Spring Harbor Laboratory, New York, 1982.

10) H. Ito, Y. Fukuda, K. Murata and A. Kimura, $J$. Bacteriol., 153, 163 (1983).

11) J. Messing, in "Methods in Enzymology," Vol. 101, ed. by R. Wu, L. Grossman and K. Moldave, Academic Press, New York, 1983, pp. 20-78.

12) M. L. Smith, J. Z. Sanders, R. J. Kaiser, P. Hughes, C. Dodd, C. R. Connell, C. Heiner, S. B. H. Kent and L. E. Hood, Nature, 321, 674 (1986).

13) C. Yanisch-Perron, J. Vieira and J. Messing, Gene, 33, 103 (1985).

14) K. A. Bostain, Q. Elliott, H. Bussey, V. Burn, A. Smith and D. J. Tipper, Cell, 36, 741 (1984). 